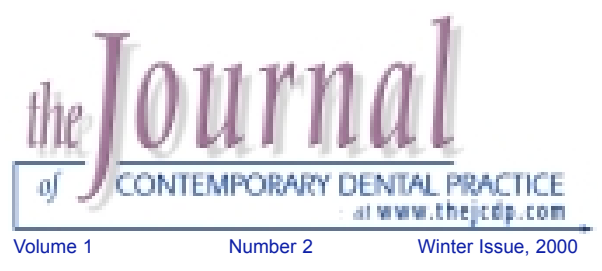

\title{
Dental Hygiene Fear: Gender and Age Differences
}

\section{Cynthia C. Gadbury-Amyot, RDH,MS; Karen B. Williams, RDH, MS}

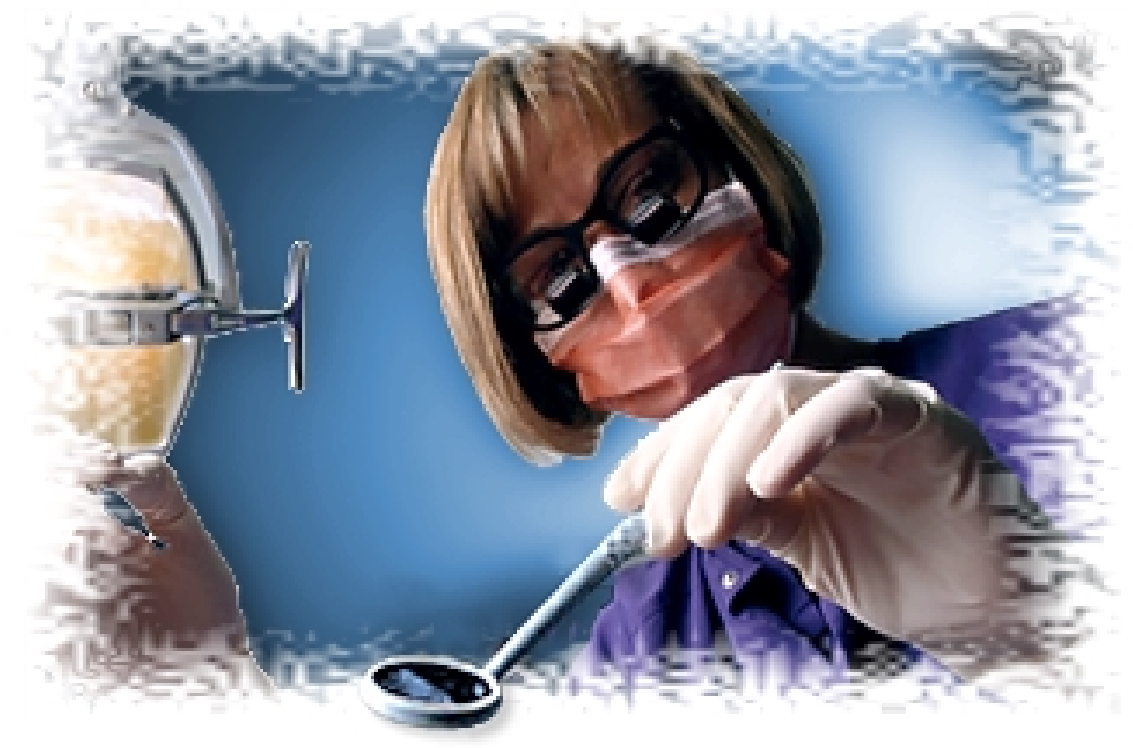

Abstract

Studies aimed at examining gender and age differences as they relate to dental anxiety have begun to appear in the literature. The purpose of this investigation was to explore fear and anxiety in a dental hygiene setting and evaluate gender and age differences among four sub-scales of dental hygiene fear.

The Dental Hygiene Fear Survey (DHFS) was developed to address patient reaction to dental hygiene treatment. The University of Washington Dental Fears Model was the theoretical model used for it identifies four domains of dental fear: fear of specific stimuli, generalized anxiety, fear of catastrophe, and distrust.

Males and females respond differently to dental hygiene treatment with women reporting significantly $(p<.05)$ greater fear overall than males. Examination of the four dental hygiene fear sub-scales show that females report greater fear $(p<.05)$ in relation to specific fear and generalized anxiety. There were no significant differences across age categories on total fear scores or within any of the sub-scales.

Characterization of the dental hygiene fear patient along with knowledge of procedures that elicit anxiety can assist the practitioner in recognizing dental hygiene-related fear. With this foundation, the practitioner can then develop management strategies specific to this phenomenon.

Keywords: Dental fear, dental hygiene fear, fear, anxiety, dental fears survey, dental hygiene fear survey, University of Washington Dental Fears Model 


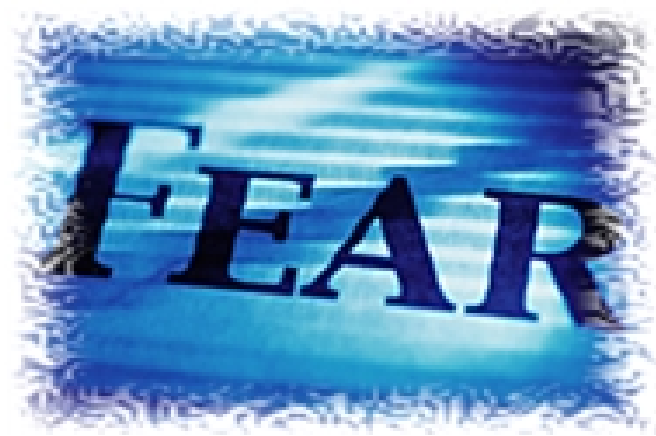

Introduction

Despite advances in patient management and pain control, dental fear and anxiety continue to create problems for patients and clinicians alike. Dental fear interferes with the provision of oral healthcare and can cause patients to delay, or even avoid necessary care altogether. Research has established that high levels of dental fear and anxiety are correlated with longer intervals between dental visits, poorer oral function and esthetics, and a higher frequency of oral symptoms. . $^{1,2,3,4,5}$ While the majority of dental fear research has focused on the prevalence, origin, and consequences of dental fear and anxiety, a new body of literature has emerged in recent years.

More studies aimed at examining gender and age differences as they relate to dental anxiety have been done in recent years as practitioners and researchers seek effective, individualized management strategies to meet the needs of diverse patient populations. Two consistent findings in this area of study are: (1) females reporting dental fear and anxiety more frequently than males and (2) an inverse relationship existing between dental fear/anxiety and age. ${ }^{1,6,7}$

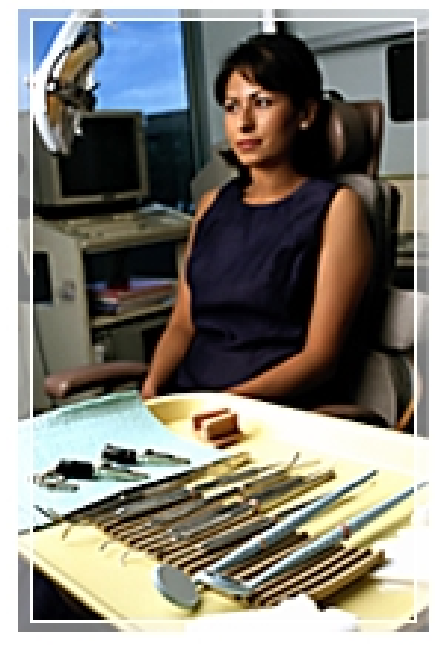

In a cross-sectional study of women's health in Sweden, Hagglin et al. investigated dental anxiety and utilization practices, oral health, and oral symptoms of the participants. ${ }^{1}$ There was a significant difference in level of dental anxiety related to age with older women reporting less fear. Liddell et al. examined the relationships of gender and age on dental anxiety in a Canadian population and found that older adults reported less painful experiences with dental procedures than younger participants. ${ }^{6}$ It was hypothesized that older adults have had more time for good experiences to neutralize aversive experiences, and this accounted for a lower reporting of pain. The most significant contributor to anxiety for both genders was fear of pain. Women subjects reported more anxiety about pain than men, but an examination of predictors of fear/anxiety showed that painful experiences were ranked as greater in importance for men than women and that intolerance of pain was a significant predictor of dental anxiety for men alone.

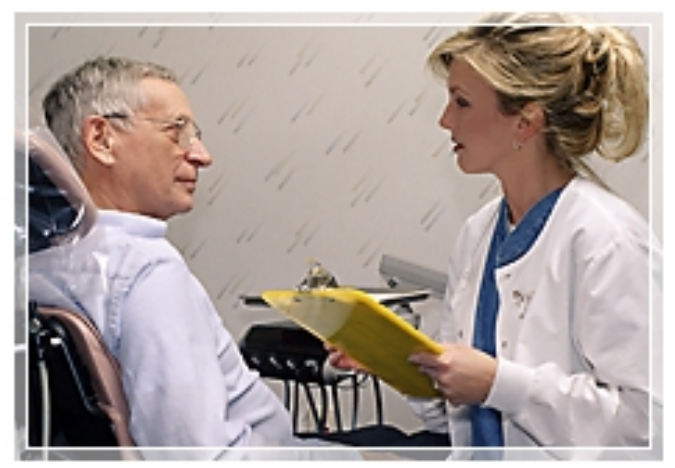

Loss of control has been identified in several studies as another significant predictor of fear. ${ }^{6,8,9}$ Liddell et al. reported perceived lack of control was the second largest predictor of dental fear and anxiety in their study participants. ${ }^{6}$ However, women demonstrated significantly greater desire for control than men. The authors concluded that women appear to be at a greater disadvantage than men in their perceived ability to cope in a dental situation because of their greater desire for control, coupled with a lower perception of actual control. They suggest this situation creates a psychological tension in women resulting in greater fear and anxiety. In contrast, older subjects reported less desire for control in the dental setting compared to younger subjects and felt greater control while in the dental environment than younger participants. Similar findings were reported by Law et al., where subjects who had a high desire for control coupled with a low feeling of control were the most dentally anxious. ${ }^{9}$ 


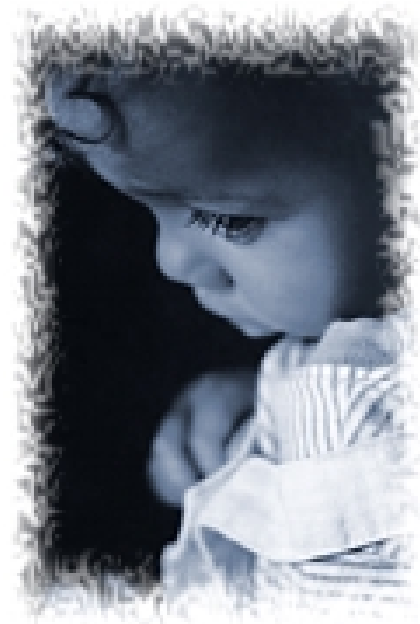

Dental fears literature has consistently shown that a large percentage of dentally fearful individuals attribute a traumatic or negative dental experience in childhood as a major contributor to their fear and anxiety of the dental setting. ${ }^{2,10}$ Walker et al. examined the association between nondentally related childhood and adult traumatic experiences (i.e., sexual, physical and emotional abuse, and neglect) in women and subsequent dental fear or anxiety. ${ }^{8}$ Results indicated that women with a higher prevalence of child maltreatment and adult sexual and physical assault had significantly higher levels of dental fear. These patients reported fear of being trapped in the dental chair, feeling claustrophobic, unable to breathe, or experiencing choking or severe gagging which subsequently interfered with the provision of dental treatment. The authors concluded that for these patients, a sense of helplessness and lack of control appear to be related to their dentally related fear.

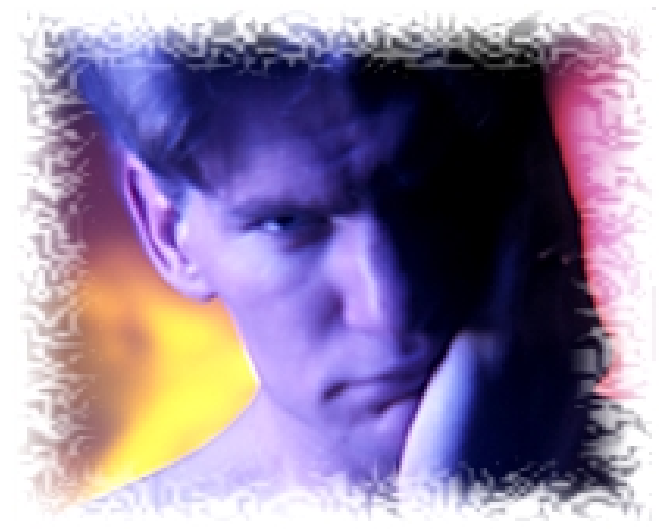

Recently, fear as it relates to dental hygiene treatment has become an area of focus as researchers have begun to consider the patient's reaction to the dental hygienist. De Jongh and Stouthard examined anxiety of patients in an Amsterdam

(Netherlands) general health center and found that a majority of the participants reported feelings of anxiety during dental hygiene treatment. The highest anxiety ratings were given to actual feelings of pain. ${ }^{11}$ This finding concurs with that of Liddell et al. where individuals receiving dental treatment ranked pain as the greatest source of their dental anxiety. ${ }^{6}$ Individual's feelings of anxiety, prior to and following treatment, were greater in response to dental hygiene treatment than to dental treatment. There was no interaction between anxiety level and gender. Both men and women experienced similar reactions to dental hygiene treatment. A study conducted by Gadbury-Amyot et al. examined dental hygiene fear utilizing a modification of the dental fears survey. ${ }^{12}$

The prevalence of fear in a dental hygiene patient population was comparable to that found for patients with dental fear. This study found that $19.3 \%$ of the participants responded by indicating high dental hygiene fear values on the survey. Tripp et al. examined dental hygiene patient's pain reports for routine clinical procedures during treatment. ${ }^{13}$ Approximately $25 \%$ of participants experienced pain ranging from moderate to severe for at least one dental hygiene procedure. The highest pain ratings were reported for probing and manual/ultrasonic scaling procedures.

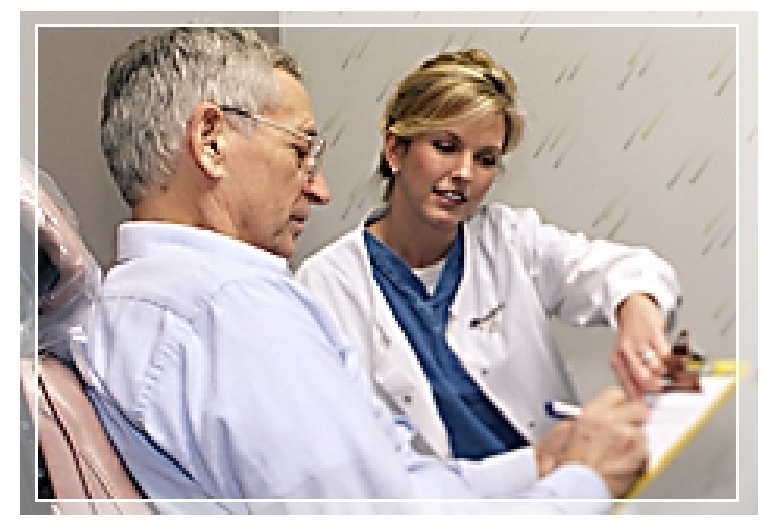

\section{Materials and Methods}

\section{Subjects}

A convenience sample of 300 dental hygiene patients from a Midwestern metropolitan area was utilized. Surveys were collected at two sites: 150 at a general dental practice located in an affluent suburb and 150 from a dental school intramural faculty practice located within the city limits. 


\section{Questionnaire}

The Dental Hygiene Fears Survey (DHFS) was used in this study. The DHFS has demonstrated good reliability and construct validity as described in detail previously. ${ }^{12}$ The survey consists of a 16item instrument with four sub-scales; fear of specific stimuli, generalized anxiety, distrust, and catastrophe, and uses a Likert-type rating scale from $1-5$, with $1=$ "not at all," to $5=$ "very much." The four sub-scales were developed utilizing the University of Washington Model for dental fear as a theoretical framework. ${ }^{14}$ Based on this theoretical framework, generalized anxiety is defined as those patients who find many different situations difficult and stressful. Specific fear is defined as a fear of being unable to tolerate a dental procedure, or the pain that the patient associates with dental treatment. The domain of distrust includes patients who experience a loss of self-esteem as a result of perceived belittlement, a feeling of helplessness and victimization, or suspicion and doubt of what the oral healthcare provider says or does. All of the above definitions for distrust reflect communication failures. Lastly, fear of a medically overwhelming catastrophe is based on a fear of having an uncontrollable bodily reaction to dental treatment such as a heart attack, choking, or an allergic reaction. Some of the items for the DHFS were adapted from Kleinknecht's Dental Fears Survey15 to specifically address the individual's reaction to dental hygiene treatment. Additional questions were developed in an attempt to more fully assess the four domains. Procedures for administration of the survey has been previously reported. ${ }^{12}$

\section{Data Analysis}

Descriptive statistics were used to characterize the sample population. There were no differences between the two data collection sites, so data was combined for analysis. Summary statistics are reported for age and gender differences on the four sub-scales and total dental hygiene fear scores. A two-factor MANOVA was used to examine the effects of gender and age and their interaction across the four sub-scales of the DHFS. Univariate ANOVAs were used post hoc to examine effects found to be significant by MANOVA. An alpha level of .025 was set to control for inflated family wise error rates for univariate ANOVAs.

\section{Results}

\section{Demographics of Sample}

Demographic characteristics are illustrated in (Table 1) and have been previously reported. ${ }^{12} \mathrm{~A}$ majority of the respondents were female $(59 \%)$.

The highest proportion of participants were in the $30-39$ age group (29\%); the lowest was in the $50-$ $59(8 \%)$ group. The predominant self-reported ethnicity $(75 \%)$ was Caucasian, followed by African American (13\%). The majority of individuals reported some college (30\%), with $26 \%$ indicating acquisition of a baccalaureate degree. 
Table 1

\begin{tabular}{|c|c|}
\hline Characteristic & $\begin{array}{l}\text { No. }(\%) \text { of Respondents } \\
(\mathrm{N}=300)^{*}\end{array}$ \\
\hline $\begin{array}{l}\text { Gender } \\
\begin{array}{c}\text { Female } \\
\text { Male }\end{array}\end{array}$ & $\begin{array}{l}174(59) \\
123(41)\end{array}$ \\
\hline $\begin{array}{l}<20 \\
20-29 \\
30-39 \\
40-49 \\
50-59 \\
\geq 60\end{array}$ & $\begin{array}{l}27(9) \\
61(20) \\
86(29) \\
74(25) \\
24(8) \\
28(9)\end{array}$ \\
\hline $\begin{array}{l}\text { Ethnicity } \\
\text { Caucasian } \\
\text { African-American } \\
\text { Hispanic } \\
\text { Asian-Pacific Islander } \\
\text { American Indian } \\
\text { Other }\end{array}$ & $\begin{array}{l}225(75) \\
39(13) \\
14(5) \\
9(3) \\
3(1) \\
9(3)\end{array}$ \\
\hline $\begin{array}{l}\text { Education } \\
\text { <High School } \\
\text { Some College } \\
\text { Associate } \\
\text { Baccalaureate } \\
\text { Masters } \\
\text { PhD }\end{array}$ & $\begin{array}{l}54(18) \\
90(30) \\
27(9) \\
78(26) \\
35(12) \\
13(4)\end{array}$ \\
\hline \multicolumn{2}{|c|}{$\begin{array}{l}\text { * The numbers do not total } 300 \text { for all characteristics becausesome respondents } \\
\text { did not answer all questions. The effect of gender on the four sub-scales } \\
\text { (Figure 1) is shown in (Table 2). Females reported significantly greater fear } \\
\text { of dental hygiene treatment overall. More specifically, females reported } \\
\text { greater fear in relation to the specific fear and generalized anxiety sub-scales. }\end{array}$} \\
\hline
\end{tabular}




\section{Sub-scale Items}

\section{Generalized Anxiety Sub-scale}

- Thinking of the dental appointment days ahead.

- Worrying about the dental hygienist hurting me.

- Worrying if the dental hygienist will get me numb before he/she scrapes my teeth.

- Thoughts of fainting or body out of control.

\section{Specific Fear Sub-scale}

- Sight of cleaning instruments.

- Sound of instruments scraping on teeth.

- Sight of the anesthetic needle.

- Feel of the anesthetic needle.

\section{Distrust Sub-scale}

- Having no control over appointment.

- Dental hygienist telling me I have gum disease or other "bad" news.

- Remarks made by the dental hygienist about oral self care.

- Feeling hygienist isn't completely honest about needed dental work.

\section{Catastrophe Sub-scale}

- Thoughts of choking on dental objects.

- Fear of dying in dental chair.

- Thoughts that might not survive

- Thoughts of "bad" reaction to novocaine.

Table 2: Means and Standard Deviations for Gender on the Dental Hygiene Fear Total and Subscale Scores: Generalized Anxiety, Specific Fear, Distrust and Catastrophe

\begin{tabular}{|l|c|c|c|}
\hline \multicolumn{1}{|c|}{ Sub-scale \& Item Scores } & $\begin{array}{c}\text { Males } \\
\text { Mean (s.d.) }\end{array}$ & $\begin{array}{c}\text { Females } \\
\text { Mean (s.d.) }\end{array}$ & p-value \\
\hline Total Fear & $23.9(9.1)$ & $27.5(10.9)^{*}$ & .038 \\
\hline Generalized Anxiety Sub-scale & $5.1(2.2)$ & $6.1(3.1)^{*}$ & .000 \\
\hline Specific Fear Sub-scale & $6.9(4.1)$ & $8.5(4.9)^{*}$ & .008 \\
\hline Distrust Sub-scale & $6.0(2.6)$ & $6.5(2.8)^{*}$ & .555 \\
\hline Catastrophe Sub-scale & $4.7(1.6)$ & $5.1(2.0)^{*}$ & .091 \\
\hline Statistically significantly greater for females (ANOVA p<.05) \\
\hline
\end{tabular}

While there were no significant differences between genders on total scores for the distrust and catastrophe sub-scales, examination of the individual items revealed significant differences, with females reporting greater fear of losing control and worrying about choking or having a bad experience with anesthesia (Table 3). 
Table 3: Summary Statistics for Sub-scales and Individual Items Division of Dental Hygiene

\begin{tabular}{|c|c|c|c|}
\hline SUB-SCALE SCORES & $\frac{\text { Males }}{\text { Mean (s.d.) }}$ & $\frac{\text { Females }}{\text { Mean (s.d.) }}$ & p-value \\
\hline Generalized Anxiety Sub-scale & $5.1(2.2)$ & $6.1(3.1)^{*}$ & .000 \\
\hline Thinking of the dental appointment days ahead. & $1.4(.74)$ & $1.8(1.0)^{*}$ & .001 \\
\hline Worrying about the dental hygienist hurting me. & $1.4(.74)$ & $1.8(1.0)^{*}$ & .001 \\
\hline Worrying if the dental hygienist will get me numb. & $2.0(.22)$ & $2.0(.21)$ & .833 \\
\hline Thoughts of fainting or body out of control. & $1.2(.63)$ & $1.4(.90)^{*}$ & .000 \\
\hline Specific Fear Sub-scale & $6.9(4.1)$ & $8.5(4.9)^{*}$ & .008 \\
\hline Sight of cleaning instruments. & $1.3(.61)$ & $1.5(.90)^{*}$ & .000 \\
\hline Sound of instruments scraping on teeth. & $1.6(1.0$ & $2.1(1.3)^{*}$ & .002 \\
\hline Sight of the anesthetic needle. & $1.9(1.2)$ & $2.4(1.3)$ & .460 \\
\hline Feel of the anesthetic needle. & $2.1(1.2)$ & $2.5(1.3)$ & .071 \\
\hline Distrust Sub-scale & $6.0(2.6)$ & $6.5(2.8)$ & .555 \\
\hline Having no control over appointment. & $1.4(.84)$ & $1.5(1.0)^{*}$ & .011 \\
\hline $\begin{array}{l}\text { Dental hygienist telling me I have gum disease } \\
\text { or other "bad" news. }\end{array}$ & $1.8(1.1)$ & $2.1(1.2)$ & .413 \\
\hline Remarks made by the dental hygienist about oral self care & $1.5(.83)$ & $1.7(1.0)$ & .081 \\
\hline $\begin{array}{l}\text { Feeling hygenist isn't completely honest about } \\
\text { needed dental work. }\end{array}$ & $1.2(.60)^{*}$ & $1.1(.90)$ & .003 \\
\hline Catastrophe Sub-scale & $6.0(2.6)$ & $6.5(2.8)$ & .555 \\
\hline Thoughts of choking on dental objects. & $1.2(.70)$ & $1.4(.81)^{*}$ & .001 \\
\hline Fear of dying in dental chair. & $1.0(.34)$ & $1.1(.50)$ & .146 \\
\hline Thoughts that might not survive. & $1.1(.40)$ & $1.1(.60)$ & .144 \\
\hline Thoughts of "bad" reaction to novocaine. & $1.3(.70)$ & $1.5(1.0)^{*}$ & .004 \\
\hline \multicolumn{4}{|l|}{ Statistically significant at $p<.05$} \\
\hline
\end{tabular}

(Table 4) illustrates the effect of age on the four sub-scales. There were no significant differences across all age categories on total fear scores and no difference within any of the sub- scales. Further, neither age nor the interaction between age and gender were found to be significant (Figure 2). 
Table 4: Means and Standard Deviations for Age Groups on the Dental Hygiene Fear Total and Sub-scale Scores: Generalized Anxiety, Specific Fear, Distrust and Catastrophe

\begin{tabular}{|c|c|c|c|c|c|c|}
\hline $\begin{array}{l}\text { Total and Sub-scale: } \\
\text { Mean (s.d.) Scores }\end{array}$ & $\begin{array}{c}<19 \\
(n=27)\end{array}$ & $\begin{array}{l}20-29 \\
(n=60)\end{array}$ & $\begin{array}{l}30-39 \\
(n=86)\end{array}$ & $\begin{array}{c}40-49 \\
(n=74)\end{array}$ & $\begin{array}{l}50-59 \\
(n=24)\end{array}$ & $\begin{array}{c}\geq 60 \\
(n=27)\end{array}$ \\
\hline Total Fear Score & $27.9(12.9)$ & $26.7(11.0)$ & $25.5(9.5)$ & $26.7(9.9)$ & $26.8(13.0)$ & $20.9(5.6)$ \\
\hline Generalized Anxiety & $6.6(3.8)$ & $5.8(3.0)$ & $5.4(2.5)$ & $5.9(2.6)$ & $6.2(3.3)$ & $4.5(.93)$ \\
\hline Specific Fear & $8.3(4.4)$ & $8.3(4.0)$ & $7.8(3.8)$ & $8.0(4.0)$ & $8.0(4.3)$ & $5.8(2.6)$ \\
\hline Distrust & $6.3(2.9)$ & $6.2(2.7)$ & $6.4(3.0)$ & $6.5(2.7)$ & $6.0(3.1)$ & $5.1(1.7)$ \\
\hline Catastrophe & $5.1(2.4)$ & $5.0(1.9)$ & $4.8(1.5)$ & $5.1(1.8)$ & $5.1(2.3)$ & $4.3(1.2)$ \\
\hline
\end{tabular}

Figure 2: Comparison of Mean Total Dental Hygiene Fear Scores for Males and Females at Different Age Groupings

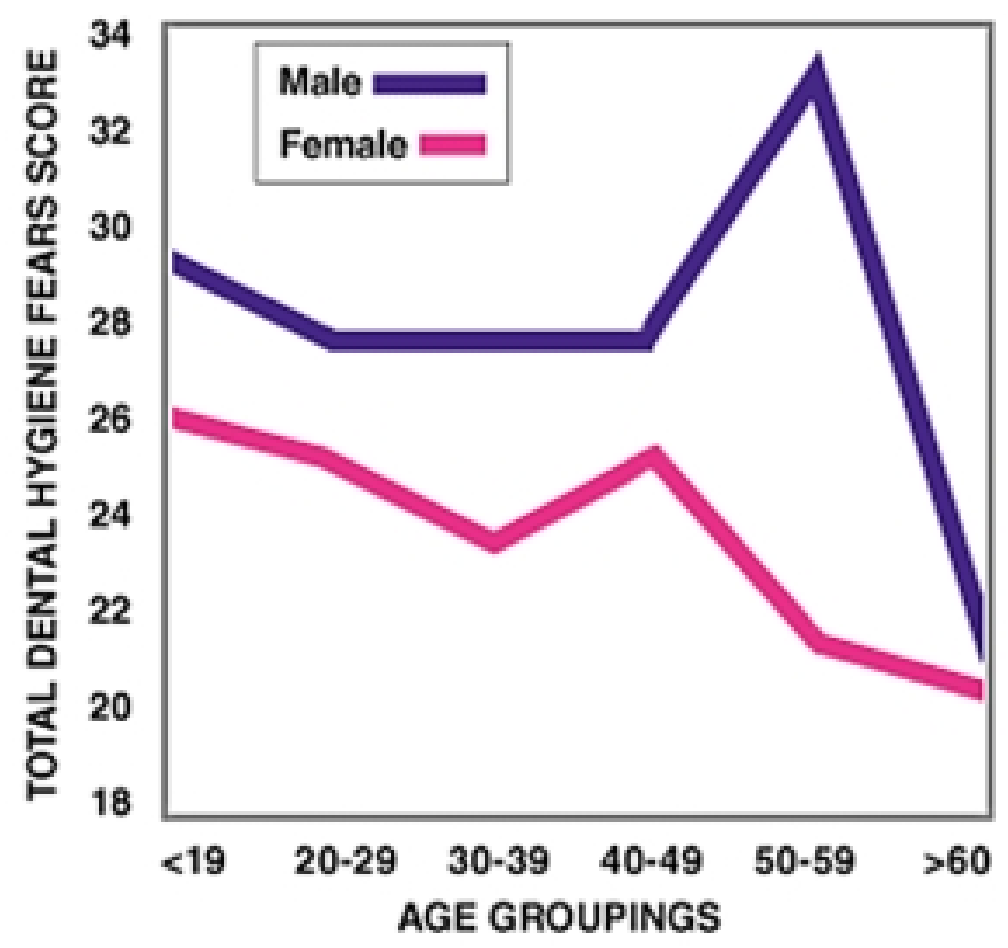

* No statistically significant difference when comparing age by gender (MANOV $\mathrm{p}=.223$ ) 


\section{Discussion}

Several researchers have demonstrated differences between genders in reporting dental fear and anxiety. Similar results were found in the current study examining patient fear and anxiety related to dental hygiene treatment. Females reported significantly higher levels of dental hygiene treatment fear than males. This finding is also consistent with psychological literature which has shown that women express more fears than men. ${ }^{16}$ Because males may not express their fears as openly as females, the practitioner should be more vigilant for possible manifestations of fear. Exaggerated emotions such as anger or impatience may be a mask for fear.

Beyond the analysis of total fear scores, the current study examined gender differences in relation to the four dental hygiene fear sub-scales.

Holtzman et al. found that females reported a significantly higher degree of fear in response to dental care in the area of specific stimuli (feel of needle, feel of drill) and feelings attributed to generalized anxiety (approaching the office). These findings were similar to those found in the current study on dental hygiene patients. This might suggest that patient's reactions whether in relation to the dentist or dental hygienist are similar.

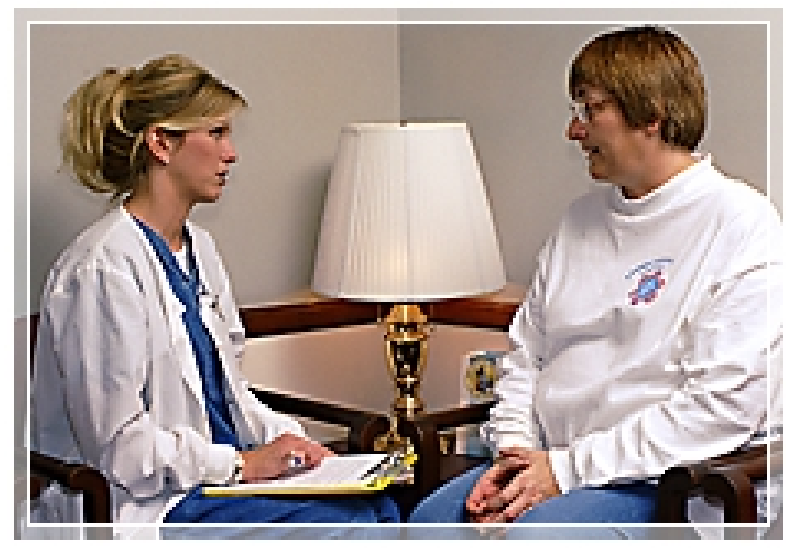

Examination of the individual items which compose the generalized anxiety sub-scale shows a somewhat greater response by females with regard to such issues as: thinking about the dental hygiene appointment days ahead; worrying about being hurt by the dental hygienist; and thoughts of fainting or body out of control. Liddell et al. hypothesized that gender differences in regard to dental pain could be due to difference in the perception of meaning of painful experiences. ${ }^{6}$
Medical and psychological research on human responses to pain (nociceptive) stimuli has generally found that women report higher levels (lower thresholds) and exhibit less tolerance for pain at given stimulus intensities than men. ${ }^{17,18}$ These findings provide evidence for the importance of good pain control measures for the dental hygiene appointment, not only for the prevention of actual pain, but also to create a positive environment where patients don't worry about their appointments days ahead or worry about being hurt.

Walker et al. has suggested that women with a past history of abuse report higher levels of dental fear and concludes that a sense of helplessness and lack of control appear to contribute to these feelings. ${ }^{8}$ The connection between dental fear and loss of control has been validated in much of the literature on dental fears. In the current study, females indicated a greater response to survey items related to thoughts of fainting or body out of control, having no control over the appointment and thoughts of choking on dental objects (Table 3).

The DHFS could be a valuable tool for the practitioner. It elicits information from the patient regarding specific triggers that provoke a fear response. This information can be used in the implementation of management strategies that help the patient cope with their fears and ultimately receive necessary treatment. This research domain substantiates the need for a multidisciplinary approach to treating dental and dental hygiene fear patients. A suspected history of abuse would best be managed by a team approach that involves the expertise of psychologists and dental professionals.

An ANOVA found no statistical difference between age categories in relation to total dental hygiene fear scores or any significant differences within the four sub-scales. (Figure 2) shows that while fear totals peaked for women in the 50-59 age category, there was no significant interaction between age and gender.

While there were no significant findings, (Table 4) illustrates a trend toward lower reporting of dental hygiene fear by both males and females as age increases. Again, these findings support the concept that patients respond similarly whether seeking dental or dental hygiene treatment. 


\section{Conclusion}

Individuals cannot be completely healthy unless they are free from the burden of oral disease.

Dental fear and anxiety have been identified as one of the principal barriers for individuals seeking needed dental care (Healthy People 201020). Continued characterization of dental and dental hygiene fear patients is necessary to assist the practitioner in identifying and subsequently managing diverse patient populations.

This study demonstrated that male and female subjects reacted differently to dental hygiene treatment with females reporting greater fear and anxiety overall. Females reported a more extreme response in the domains of specific fear and generalized anxiety. Age was not a significant factor in the patient's reaction to dental hygiene treatment.

Further investigation of differences in gender response to dental and dental hygiene fear and pain is needed. Additional research into the relationship between a history of abuse and dental and dental hygiene fear could also provide valuable information for the management of patients

\section{References}

1. Hagglin C, Berggren U, Hakeberg M, Ahlqwist M. Dental anxiety among middle-aged and elderly women in Sweden. A study of oral state, utilization of dental services and concomitant factors. Gerodontology 1996; 13: 25-34.

2. Milgrom P, Fiset L, Melnick S, Weinstein P. The prevalence and practice management consequences of dental fear in a major U.S. city. J Am Dent Assoc 1988; 116: 641-647.

3. Berggren U, Meynert G. Dental fear and avoidance: Causes, symptoms, and consequences. J Am Dent Assoc 1984; 109: 247-251.

4. Dionne R, Gordon S, McCullagh L, Phero J. Assessing The Need For Anesthesia and Sedation In The General Population. J Am Dent Assoc 1998; 129: 167-173.

5. ter Horst G, de Wit CA. Review of behavioral research in dentistry 1987-1992: dental anxiety, dentist-patient relationship, compliance and dental attendance. Int Dent J 1993; 43: 265-78.

6. Liddell A, Locker D. Gender and age differences in attitudes to dental pain and dental control. Community Dent Oral Epidemiol 1997; 25: 314-8.

7. Holtzman J, Berg R, Mann J, Berkey D. The relationship of age and gender to fear and anxiety response to dental care. Spec Care Dentist 1997; 17: 82-87.

8. Walker E, Milgrom P, Weinstein P, Getz T, Richardson R. Assessing Abuse and Neglect And Dental Fear In Women. J Am Dent Assoc 1996; 127: 485-490.

9. Law A, Logan H, Baron RS. Desire for control, felt control, and stress inoculation training during dental treatment. J Pers Soc Psychol 1994; 10: 926-36.

10. Locker D, Liddell A. Correlates of dental anxiety among older adults. J Dent Res 1991; 70: 198-203.

11. De Jongh A, Stouthard MEA. Anxiety about dental hygienist treatment. Community Dent Oral Epidemiol 1993; 21: 91-95.

12. Gadbury-Amyot C, Overman P, Carter-Hanson C, Mayberry W. An Investigation of Dental Hygiene Treatment Fear. J Dent Hyg 1996; 70: 115-121.

13. Tripp D, Neish N, Sullivan M. What Hurts During Dental Hygiene Treatment. J Dent Hyg 1998; 72: 25-30.

14. Milgrom P, Weinstein P, Kleinknecht R, Getz T. Treating Fearful Dental Patients-A Patient Management Handbook. Reston, Virginia; 1995.

15. Kleinknecht R, Bernstein D. Assessment of dental fear. Behav Ther 1978; 9: 626-634.

16. Brink-Muinen A, Bensing J, Kerssens J. Gender and Communication Style in General Practice: Differences Between Women's Health Care and Regular Health Care. Med Care 1998; 36: 100-106.

17. Law S, Britten N. Factors that influence the patient centeredness of a consultation. Br J Gen Pract 1995; 45: 520-524.

18. Arnold RM, Martin SC, Parker RM. Taking care of patients-does it matter whether the physician is a woman? West J Med 1988; 149: 729-36.

19. Pickersgill M, Valentine J, May R, Brewin C. Fears in mental retardation : I. Types of fears reported by men and women with and without mental retardation. Adv Behav Res Ther 1994; 16: 277-296.

20. "Healthy People 2010." Retrieved November 16, 1999 from the World Wide Web http://www.health.gov/healthypeople/ 


\section{About the Authors}

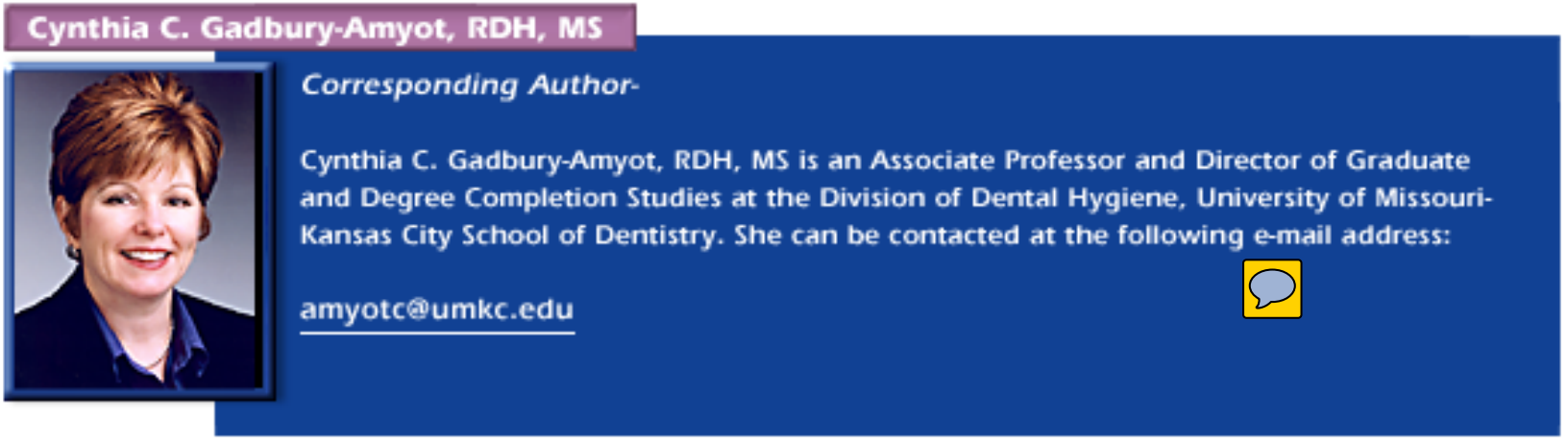

Karen B. Williams, RDH, MS

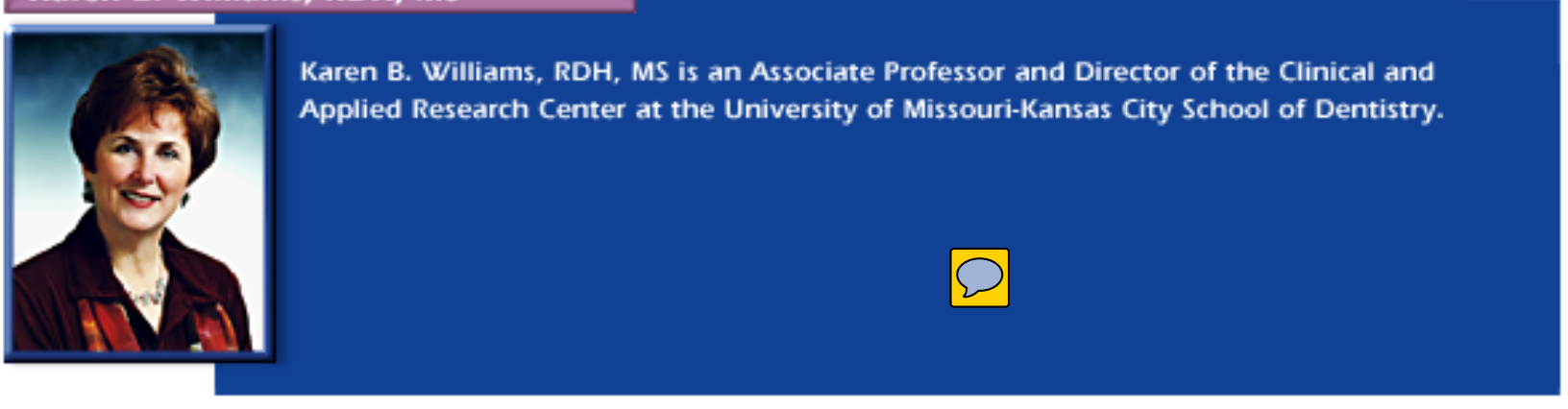

